\title{
Dialectical Features of Students' Argumentation: A Critical Review of Argumentation Studies in Science Education
}

\author{
Jan Alexis Nielsen
}

(C) Springer Science+Business Media B.V. 2011

\begin{abstract}
This paper explores the challenges of using the Toulmin model to analyze students' dialogical argumentation. The paper presents a theoretical exposition of what is involved in an empirical study of real dialogic argumentation. Dialogic argumentation embodies dialectical features - i.e. the features that are operative when students collaboratively manage disagreement by providing arguments and engaging critically with the arguments provided by others. The paper argues that while dialectical features cannot readily be understood from a Toulminian perspective, it appears that an investigation of them is a prerequisite for conducting Toulminian analysis. This claim is substantiated by a detailed review of five of the ten most significant papers on students' argumentation in science education. This leads to the surprising notion that empirical studies in the argumentation strand - even those studies that have employed non-dialectical frameworks such as the Toulmin model - have implicitly struggled to come to terms with the dialectical features of students' discourse. The paper finally explores how some scholars have worked to attend directly to these dialectical features; and it presents five key issues that need to be addressed in a continued scholarly discussion.
\end{abstract}

Keywords Science education · Argumentation · Dialogue $\cdot$ Dialectics $\cdot$ Toulmin

\section{Introduction}

Most scholars of the argumentation strand in science education agree that the strand's dominant analytical framework - the Toulmin model — does not properly guide analysts on how to distinguish between the elements - claim, data, warrant and so on - that Toulmin (1958) thought constituted an argument (e.g. Duschl 2007; Erduran 2008; Erduran et al. 2004; Jiménez-Aleixandre et al. 2000). Some scholars have even hinted that interesting discursive aspects may become lost in translation when the Toulmin model is used to reduce the dialogic nature of students' argumentation into passive patterns of

\footnotetext{
J. A. Nielsen $(\bowtie)$

University of Southern Denmark, Campusvej 55, 5230 Odense M, Denmark

e-mail: janalexisnielsen@gmail.com
} 
arguments (e.g. Hofstein et al. 2008; Naylor et al. 2007; Walker and Zeidler 2007). Though some review articles have mentioned these problems (e.g. Bricker and Bell 2008; Sampson and Clark 2008), there is to date no science education paper that has crafted a detailed review of the analytical problems that arise from using the Toulmin model on recorded argumentation. This is unfortunate because such an effort could shed light on some fundamental issues of concern within the argumentation strand. For there is a general tendency in how scholars have reacted to the problems of the Toulmin model by adjusting the model and adjusting the manner in which they have analyzed argumentation. By reviewing in detail five of the ten most significant papers of the argumentation strand, this paper argues that the argumentation strand consistently has struggled to come to terms with the dialectical features of students' dialogic argumentation. The paper argues, further, that it is warranted to have a thorough scholarly discussion about how to study and analyze dialogical argumentation.

The dialectical features of students' dialogic argumentation refer in this context to the features that are operative when students collaboratively manage (potential) disagreement by providing arguments and engaging critically with the arguments provided by others. There are a number of reasons for why the argumentation strand in science education should focus on these dialectical features. It has been argued that if the aim of education is to foster the development of rational agents, it involves enabling students to be attentive to their dialectical obligations of providing adequate argumentation and engaging with the argumentation of others (Siegel 1995). It has been argued that dialectical argumentation is part and parcel of scientific debate (Pera 1994) — indicating that the approbation of the skills for such argumentative discourse should be a prime aim of science education. Within social psychology, it has been demonstrated that the dialectical processes that students go through upon having their standpoints challenged by peers can aid the construction of more detailed disciplinary knowledge, changing or revisiting world views, and the development of more appropriate ways of reasoning (Orsolini and Pontecorvo 1992; Pontecorvo and Girardet 1993; Pontecorvo and Pirchio 2000). This seems to be the case especially if such processes involve negotiation and conciliation attempts (Leitão 2000, 2001). Finally, within science education it has been argued that the promotion of scientific reasoning would benefit from an "emphasis on the [...] dialogue logic found in dialectical contexts" (Duschl 2007, p. 172).

On the face of it, only few studies in the argumentation strand have investigated the dialectical features of students' dialogic argumentation. But this is not completely correct. This paper argues that scholars of the argumentation strand have more or less been forced to attend to dialectical features of students' argumentative discourse and that this is true even for the studies that have applied the Toulmin model. Further, the paper argues that — until recently — it has typically been the problems of the Toulmin model that have forced analysts to conduct dialectical interpretation in the first place. Finally, the paper argues that the interpretive efforts and decisions of the analysts who have attended to the dialectical features of dialogic argumentation have — with a few exceptions - remained largely implicit. The paper begins with a theoretical exposition of dialogical argumentation and the Toulmin model. The paper then reviews in detail some of the most significant contributions to the argumentation strand. Lastly, the paper reviews a few studies that have explicitly had dialectical features of students' dialogic argumentation as their object of study. On the basis of the review of theory and of empirical studies the paper proposes five key issues that the continued scholarly debate in the argumentation strand needs to address. 


\section{Dialogic Argumentation as an Object for Empirical Studies}

In the first instance, argumentation is an activity — something persons do - while an argument is the product that can be distilled from that activity (e.g. O'Keefe 1977; van Eemeren and Grootendorst 2004). In most definitions, argumentation is treated as a social activity, which is rationally guided, and primarily comprised of utterances (or speech acts) (e.g. Johnson 2002; van Eemeren et al. 1987). When one studies actual argumentative discourse it is important to distinguish between monologic and dialogic argumentation. Following Goldman (1999), this paper draws this distinction at the minimal level of the context of the argumentation: while "monological argumentation [is] a stretch of argumentation with a single speaker [...] dialogical argumentation [is a stretch of argumentation] in which two or more speakers discourse with one another" (p. 131).

Most scholars in the argumentation strand - including those who have applied the Toulmin model — have explicitly embraced students' dialogic argumentation as their primary object of study. But by dialogic argumentation, scholars in the argumentation strand have typically meant more than just the context of argumentation. For example, Duschl and Osborne (2002) defined dialogic argumentation as a "social and collaborative process necessary to solve problems and advance knowledge" (p. 41). Similarly, Clark and Sampson (2008) have held that "dialogic argumentation stresses collaboration over competition" (p. 296); and Erduran et al. (2004) emphasized that "the goals in promoting argumentation in science lessons is to engage learners in dialogical conversation where they can not only substantiate their claims but also refute others' with evidence" (p. 927). So, beyond occurring in a dialogic context, dialogic argumentation has been treated as a collaborative problem-solving affair that can have epistemic outputs for students. Numerous scholars in the argumentation strand have offered equivalent definitions of dialogical argumentation (e.g. Driver et al. 2000, p. 291; Erduran 2008, p. 65; Garcia-Mila and Andersen 2007, p. 32; Hofstein et al. 2008, p. 73; Jiménez-Aleixandre 2007, p. 103; Jiménez-Aleixandre and Pereiro-Muñoz 2005, p. 420; Kelly and Chen 1999, p. 885; Kolstø and Ratcliffe 2007, p. 120; Munneke et al. 2003, p. 116; Naylor, et al. 2007, p. 17; Skoumios 2008, p. 382; Zeidler et al. 2006, pp. 99-101; Zohar 2007, p. 261). Thus it has been standard in the argumentation strand to parse dialogic argumentation as a specialized way of arguing in which the participants not just defend their own claims, but also engage constructively with the argumentation of their peers. From the perspective of argumentation theory, that specialized way of arguing is typically referred to as dialectical argumentation.

\section{Dialectical Features of Dialogic Argumentation}

The term 'dialectical argument' is typically traced back to Aristotle's Topics (1997). He posited dialectical argumentation as a special form of public arguing in which two (or more) arguers elicit arguments for and against a point of view (cf. van Eemeren et al. 1987). This special form of arguing is necessary, Aristotle argued, if the premises that are used are not known to be true (cf. Smith 1993). So in cases where the conclusion cannot be inferred from the premises, dialectical argumentation is necessary to establish a rational agreement. Still today, informal logicians distinguish dialectical arguments from inferences. While the latter are certain and valid arguments with conclusions that "can be reached without accounting for others' arguments", the former is a type of dialogic argument "that arise out of the heterogeneity of other arguments" (Beard 2003, p. 255; see also Johnson 2002; van Eemeren and Grootendorst 2004; Walton 2000). Most notably, arguers who engage in dialectical argumentation interact through a register of dialectical moves such as 
questioning, elaborating, requesting justification, anticipating future reactions etc. (e.g. Johnson 2002; van Eemeren et al. 1987).

In recent years, informal logicians have widely agreed that everyday (informal) dialogic argumentation embodies dialectical features (e.g. Blair and Johnson 1987; van Eemeren and Grootendorst 1982). Thus the primary issue within informal logic has not been whether, but, rather, to which extent the notions of argumentation and argument appraisal should revolve around the notion of dialectics (Finocchiaro 2006; Johnson 2002). While some have stipulated that all argumentation should be understood as if it were part of an attempt to dialectically reach an agreement (van Eemeren and Grootendorst 2004), others have merely stipulated that the arguer has "dialectical obligations" - of anticipating and reacting to others' argumentation - that she needs to "discharge" (Johnson 2002, p. 168; see also Kock 2007b). The crux of the matter is that in cases where a given dialogic argumentative exchange involves argumentation from premises that are not evidently true, that exchange ideally embodies dialectical features — in the sense that arguers collaboratively "manage [their potential or perceived] disagreement" (Wenzel 1993, p. 1) by providing arguments for their claims and constructively engaging with the argumentation of the others (cf. Clark 1990).

\section{Dialogic Argumentation as an Object of Study: Two Kinds of Products}

Scholars of the argumentation strand have typically worked on the basis of a conceptual distinction between argumentation as a process and arguments as the products - i.e. premise-conclusion constellations - that can be distilled from the process (e.g. Berland and Mcneill 2010; Bricker and Bell 2008; Duschl and Osborne 2002; Jiménez-Aleixandre and Erduran 2007; Osborne et al. 2004; Sampson and Clark 2008; Zohar and Nemet 2002). While this distinction is both necessary and in line with a distinction drawn in argumentation theory (O'Keefe 1977; van Eemeren and Grootendorst 2004; Walton and Godden 2007), it may also confuse or conflate two very different kinds of objects of study.

For empirical investigations of dialogic argumentation it is necessary to distinguish between two kinds of products: The argument sequences that consist of the arguers' talk turns, and the argument cores - in the form of e.g. premise-conclusion patterns - that can be extrapolated from the argument sequences (see Table 1). Argument sequences - that are represented in transcriptions of the occurred dialogic argumentation - consist of an ordered series of speech acts that were exchanged among arguers in the original argumentation process. The key quality of argument sequences is their sequential nature: they consist of talk turns that represent a temporally ordered discursive process by registering who said what, at what point. From the perspective of argumentation theory, argument sequences are on par with what Walton (2000) has called "dialogue sequence[s]" (p. 340) or "sequences of rational argumentation" (p. 329) in which "reasoning [is] moving forwards" (Walton and Godden 2007, p. 8).

Argument cores are more abstract than argument sequences. Argument cores typically involve at least a conclusion or claim and one or more premises and these core elements are distilled or extrapolated by the analyst from the argumentation sequence in which they occurred. The key point is that such cores do not exist as concrete entities - they are abstractions from the recorded discourse that the analyst makes on the basis of an analytical framework. From the perspective of argumentation theory, argument cores are on par with what Ralph Johnson (2002) called the "illiative core" of an argument which is a descriptor of the level of "structure of argument" (p. 312); they denote what Willard (1989) called a “claims-reason-complex" (p. 77); and they are what Toulmin (1958) called an argument's 
Table 1 The objects of study for empirical studies on dialogic argumentation

\begin{tabular}{|c|c|c|c|}
\hline & \multicolumn{3}{|l|}{ Argumentation } \\
\hline & \multicolumn{2}{|l|}{ Product } & \multirow{2}{*}{$\frac{\text { Process }}{\text { Dialogic argumentation }}$} \\
\hline & Argument core & Argument sequence & \\
\hline Description & $\begin{array}{l}\text { The sentences that are } \\
\text { extrapolated as those who } \\
\text { play a role in the justification } \\
\text { procedure. Typically } \\
\text { involving at least a } \\
\text { conclusion and one or } \\
\text { more premises. }\end{array}$ & $\begin{array}{l}\text { The product(s) of the arguing } \\
\text { in terms of the series of } \\
\text { speech acts that were } \\
\text { exchanged among the } \\
\text { discussants. }\end{array}$ & $\begin{array}{l}\text { The process in which } \\
\text { persons elicit } \\
\text { argumentative } \\
\text { discourse about } \\
\text { some issue. }\end{array}$ \\
\hline Status & Passive things & & Activity \\
\hline \multirow[t]{2}{*}{ Temporality } & Atemporal & Temporal & \\
\hline & & Sequential & Ongoing \\
\hline Persons & Absent & Authors of talk turns & Actors \\
\hline Representation & Abstractions & Transcriptions & N/A \\
\hline
\end{tabular}

"pattern [or] shape [...] that has been presented in a series of steps conforming to certain basic rules of procedure" (p. 40). In fact, the Toulmin model is one analytical framework that describes which kinds of elements an argument core could or should consist of. Thus, analytical frameworks, such as the Toulmin model, mention generic core elements, such as claims, data, warrants, backings, qualifiers and rebuttals, and this directs the attention of the analyst to extrapolate talk units from her transcripts as talk units that may fit either of these generic core elements.

Both argument cores and argument sequences are ontologically distinct from the actually occurred dialogical argumentation process: While cores and sequences are "passive" objects, argumentation processes are "activities" (Willard 1989, p. 27). But argument sequences and argument cores are ontologically distinct from one another: While argument cores are atemporal abstractions that the analyst has extrapolated and rearranged according to an analytical framework, argument sequences are temporal in the sense that they sequentially represent the occurred argumentative exchange; and while argument sequences record who said what in which order, the speakers are "typically absent" in argument cores (Johnson 1995, p. 239). In argument cores, that is, the analyst has reduced the dialogic discourse to monological constellations of core elements.

If one is interested in the dialectical features of dialogic argumentation one has to attend to argument sequences for there is no (or at least not sufficient) information about these features stored in extrapolated core elements. The force of extrapolating cores is that it allows the analyst to abstract noise, reconstruct sentences, and freely re-arrange talk units as standing in (informal) logical relations with each other — such as the relation between claim, data, warrants etc. (Andrews 2005). But there is a trade off between (informal) logical relations and sequential situation. The extrapolation of core elements carves each reconstructed talk unit out if its sequential context. In the Toulmin model, for example, the (informal) logical relation between the core elements in an argument is intact regardless of the order in which they were uttered in the original argumentative exchange (cf. Toulmin 1958, pp. 16-7). But in order to attend to the dialectical features, the sequential context is crucial. It makes no sense to speak of the dialectics of an argumentation process without 
taking into account who spoke and in which order. For example, to thematise the dialectical move of questioning, the analyst must attend to the issues of who questioned whom about what and at what stage in the argumentative exchange. But such a thematization "cannot be accommodated, at least straightforwardly" in approaches that focus on core elements (Walton and Godden 2007, p. 10). The extrapolation of core elements is fundamentally the creation of a static layout of the argumentation; and while this has many benefits it precludes the analyst from studying her object of study as a dynamic dialectical exchange that moves forwards (e.g. Fulkerson 1996; Willard 1976; Wohlrapp 1987).

\section{The Toulmin Model}

Toulmin's (1958) model of informal argument patterns is by far the best-known framework that proposes which core elements could or should be extrapolated in the analysis of an argument. In an attempt to contest the dominance of formal logic, Toulmin (1958) aimed at expanding the "traditional" notion of logic to denote a science that can also have nonanalytical (what he calls "substantive") arguments as its object (see e.g. pp. 114ff). For Toulmin, argumentation, both analytical and non-analytical, is about the construction of "justificatory arguments" (p. 12). He was, that is, not concerned with the practical process through which persons reach conclusions, make decisions, or resolve disagreements; he was, rather, concerned with how "arguments sentence by sentence" justify such conclusions, decisions, or resolutions (p. 88). Consequently, the chief concern of the expanded science of logic that he proposed would be to scrutinize the "manner" with which arguers are "laying [their arguments] out" in order to justify claims (p. 88). The key to laying out everyday (substantive) arguments, Toulmin proposed, is to follow an ordered "procedure" (p. 21) of eliciting a number of different "elements" (the above mentioned core elements) — namely "claim", "data", "warrant", "backing", "rebuttal", and "qualifier" (p. 89-95).

Toulmin's most significant break with formal logic was to define the core elements in functional terms (cf. p. 87). Data, warrants, backings and so on have "different logical functions" because they perform different roles in the argument (p. 92). They are answers to different questions. While data-elements answer to "What have you got to go on?", warrantelements answer to "How do you get [from data to claim]?" (p. 90), backing-elements answer to "but why do you think that [the warrant is justified]?" (p. 95), and rebuttalelements answer to "[what are the] circumstances in which the general authority of the warrant would have to be set aside[?]" (p. 94).

Though The Uses of Argument (Toulmin 1958) was explicitly tentative (cf. p. 1), a vast number of scholars outside the field of argumentation theory have adopted Toulmin's model in studies of actually occurred argumentation. These different empirical studies share a roughly similar modus operandi: The Toulmin model provides a list and a description of core elements that the analyst looks for in the recorded argumentation, fitting talk units or sentences are extrapolated and rearranged to reconstruct the layout of the argument, and this resulting layout is either itself discussed and criticized or it is a part of a larger corpus of extrapolated argument cores about which something general is said.

According to Toulmin (1958), the core elements could not be extrapolated on the basis of what he called a "grammatical" interpretation (1958, p. 91). Indeed, from Toulmin's perspective, the insecurity of interpreting messy everyday argument sequences is the sine qua non for introducing the distinction between elements such as datum and warrants in terms of their logical function rather than in terms of their expressive function in spoken language (see e.g. his famous 'physiology metaphor', 1958, p. 87). As Klumpp (2006) has summarized 
on behalf of Toulmin: "the form of [a] sentence does not permit the separation [of core elements;] [y]ou cannot simply look at a sentence and tell the function it is serving" (p. 107).

Numerous scholars in argumentation theory have argued that the Toulmin model - as an analytical framework - cannot sufficiently guide an analyst to determine which of the functional questions a given talk unit answers to (e.g. Bermejo-Luque 2006; Chambliss 1995; Cooley 1959; Freeman 2005, 2009; Johnson 1981a, b; Keith and Beard 2008; Newman and Marshall 1991; Reed and Rowe 2005; Trent 1968; Verheij 2005; Willard 1976). For example, Cowan (1964) and van Eemeren et al. (1987) have pointed out that talk units that may be extrapolated as data in one case can be extrapolated as a warrant in others and vice versa; similarly Castaneda (1960), Gross (1984), and Hample (1992) have argued that that there is no meaningful functional distinction between warrants and backings. Hample (1992) summarized the contention among these critics by stating that it is "hopeless" to distinguish between the different core elements "except for the case of someone who actually says 'I have found that' and "We may take it that," and so on (p. 229). It seems to be a fundamental problem with the Toulmin model that it forces the Toulminian analyst to "engage in considerable translation to see how the argument fits" (Fulkerson 1996, p. 24); but if this translation, or interpretation, involves the manner in which arguers expressed themselves it would seem to violate Toulmin's (1958) rejection of grammatical interpretation.

Also within the argumentation strand in science education it has been acknowledged that the Toulmin model presents the analyst with interpretative difficulties of determining which core element a given talk unit should be extrapolated (as claim, data, warrant etc.) (e.g. Duschl 2007; Erduran, et al. 2004; Jiménez-Aleixandre, et al. 2000; Kelly et al. 1998; Walker and Zeidler 2007). For example, Erduran (2008) saw this difficulty as the primary issue to be handled in the argumentation strand: If you were to ask scholars of the strand about their greatest concern they would "begin to ask you if you have figured out how to distinguish data from warrants" (p. 47).

\section{Toulminian Analysis of Argument Cores in Science Education}

This section reviews some of the key contributions to the argumentation strand with the aim of shedding light on how the scholars of the strand have addressed the interpretative difficulties that the Toulmin model creates. Particular attention will be given to five of the ten most significant ${ }^{1}$ contributions to the strand: Kelly et al. (1998), Jiménez-Aleixandre et al. (2000), Driver et al. (2000), Erduran et al. (2004), and Osborne et al. (2004). The minute critical points that will be made in the following are not meant to cast doubt on the reliability of these papers. To be sure, there are very good reasons for why these papers are part of the canonical works on argumentation in science education. The points, which this paper aims to illuminate, are general points about some of the issues that the argumentation strand has struggled with since its beginning.

The use of Toulmin in the Early Works of the Argumentation Strand

Kelly et al. (1998) conducted a study of students' dyadic spoken discourse while working on a hands-on performance assessment task relating to electricity problems. Their aim was

\footnotetext{
${ }^{1}$ In terms of citations according to a March 2011 search on the terms 'science education' and 'argumentation' on The Social Sciences Citation Index, ISI Web of Knowledge, www.isiknowledge.com
} 
to investigate how students articulated evidence for their claims through scrutinizing the layout of the participating students' discourse. In particular, their aim was to devise a framework that would enable future investigations of students' discourse from the angle of argumentation. Kelly et al. (1998) revised the Toulmin model: While they did not take account of rebuttals, they added a core element called "challenge", and, finally, they divided the data-element into three different elements according to the type of information relayed in the data — "facts", "empirical data", and "hypothetical data" (p. 856).

During Kelly et al.'s (1998) analysis, it became apparent that "the identification of 'data', 'claim' and 'warrant' was a subtle affair' (p. 856). Thus they had to find a way to circumvent the problem of determining which generic core element a given talk unit should be extrapolated as. To this end, Kelly et al. (1998) "needed to consider" (i) "the place of a particular argument made by a student in the context of the conversation", (ii) "the relationship of a particular utterance to the others in the argument", and (iii) "paralinguistic cues" (p. 856; emphasis added). Now, there are unmistakable dialectical connotations in the first two considerations that Kelly et al. (1998) needed to make. Indeed, attending to the dialectical features embodied in an argument sequence is the only way to ascertain "the place" of a set of talk units, or "the relationship" between multiple talk units, in a conversational context. So the picture that emerges from Kelly et al.'s (1998) analysis is that they saw the analysis of dialectical features as a necessary foundation for a Toulminian extrapolation of core elements. Further, it were the difficulties of using the Toulmin model as an analytical framework that motivated Kelly et al.'s attention to the dialectical features of argument sequences in the first place. Indeed, as Kelly et al. (1998) stated, it was these difficulties that led the authors to consult the overall "segment of the conversation" in their efforts to layout the structure of a given argument (p. 857; emphasis added). But though it is evident that Kelly et al. (1998) "had to look backward, and often forward in the conversation" (p. 857) in order to establish how to extrapolate a given talk unit, they did not explicate what they looked for in the argument sequences and how they interpreted the sequences.

Kelly et al. (1998) to some extent also directly attended to the dialectical features of argument sequences. They wanted to derive a sort of matrix consisting of different "warranting strategies, referents and types" and different "antecedent conditions that led to warranted arguments" - i.e. different argumentative prompts (such as a question being posed, a new claim being made, the invocation of empirical data) for the invocation of evidence (p. 867). They found that students were mainly prompted to invoke evidence in support of their antecedent claim when the opponent posed a question, forwarded propositions that somehow conflicted with the antecedent claim, or provided empirical data. This is not too surprising since such moves all belong to the dialectic register of challenges that an opponent may use (van Eemeren et al. 2007). Unfortunately it is difficult to get a good sense of how Kelly et al. (1998) understood the different forms of argumentative prompts. For example, they distinguished between "statements" and "challenges", but went on to state that "[i]n either case the speaker may be affirming the previous claim [...] [or] offering an alternative interpretation" (p. 866). A challenge that affirms the claim it challenges is not straightforwardly a challenge; and in what sense are statements that offer alternative interpretation different from challenges? Maybe the authors had in mind a distinction between full negations of a claim and merely partial doubts in a claim — such as it is found in e.g. the pragma-dialectical school (van Eemeren and Grootendorst 2004) — but the text of Kelly et al. (1998) provides no further clues. Even though a part of their study involved attending directly to argument sequences it is difficult 
to get a firm sense of how they conceptualized such sequences and the dialectical features they embody, and, more importantly, how these features were interpreted.

Jiménez-Aleixandre et al. (2000) ventured to investigate "argument patterns from high school students [who were] solving genetics problems" (p. 762) in situations where the students were "doing" or "talking science" (e.g. p. 759). In order to layout students' argument patterns, Jiménez-Aleixandre et al. (2000) used a (revised) Toulmin model as a guide for extrapolating core elements from the recorded argumentation. In parallel to argument patterns, Jiménez-Aleixandre et al. also investigated students" "epistemic operations" such as "explanation procedures, causal relations, and analogies" — which the authors argued "are related to knowledge construction, specific from the science domain" (p. 763).

The first thing to note is that Jiménez-Aleixandre et al. (2000) were less explicit than Kelly et al. (1998) about the difficulties they faced when using the Toulmin model as a guide to extrapolate core elements. In fact, the authors did not mention any concrete difficulties concerning their analysis. Only in the very last sentence of the paper, JiménezAleixandre et al. (2000) raise this as an issue for future research: "A question that deserves more detailed studies is [...] "what counts" as explanation, warrant, or even data, and we are currently exploring these issues." (p. 783). So the authors did at some point come to the conclusion that it is not straightforward how different core elements in the Toulmin model should be parsed, but there is no mention of how this affected their analysis. At this point it is revealing to have a closer look at why the Jiménez-Aleixandre et al. (2000) also attended to students' epistemic operations.

While Jiménez-Aleixandre et al. (2000) initially stated that their attention to epistemic operations was motivated by their focus on developing scientific knowledge, it appears in later stages of their argument that this addendum to the Toulmin approach is motivated by some difficulties with analyzing argumentation - much akin to the difficulties that Kelly et al. (1998) faced: "The argument pattern from Toulmin was not enough to interpret some exchanges, and that is why we developed a frame for epistemic operations" (p. 783; emphasis added). Further, from the coded transcripts that JiménezAleixandre et al. (2000) present in their paper, it is evident that they extended the Toulmin model to include additional types of core elements (cf. in particular pp. 785-792): "Request" (apparently covering requests for justification as well as requests for clarification), "Oppositions" (apparently challenges to antecedent statements), "Counter-oppositions" (apparently re-assertions of an original claim that was being challenged), and "Concessions" (apparently a move that a speaker signals being convinced of the opposition to her original claim). Not only does this indicate that Jiménez-Aleixandre et al. (2000) saw the need for adjusting the Toulmin model so as to more precisely extrapolate core elements from dialogic argumentation, it also indicates that JiménezAleixandre et al. (2000) attended the dialectical features of the students' dialogic argumentation. It is worth noticing how the added core elements all denote operations or moves that can only be interpreted from a dialectical perspective and by attending to the argument sequences. Unfortunately Jiménez-Aleixandre et al. (2000) did not describe or discuss these additional core elements in detail. The added elements appear however to be adopted from the "argumentative operations" that Pontecorvo and Girardet added to the Toulmin model (see e.g. Pontecorvo and Girardet 1993, p. 373); but from Jiménez-Aleixandre et al.'s (2000) text it is difficult to ascertain why and how they were used.

In another paper, Duschl (Duschl et al. 1999) - the third author of Jiménez-Aleixandre et al. (2000) - explicitly denounced the adjusted Toulmin model that was used by 
Jiménez-Aleixandre et al. (2000). Duschl et al. (1999) reported that when they applied "Toulmin's argument pattern to analyze group reasoning" they

found that the analysis of discourse employing argumentative and epistemic operations did not adequately distinguish signal from noise. Consequently, distinguishing the structure and patterns of argument was difficult. [...] The dialectical nature of the group interview made the assignment of analytic epistemic operations like definition, categorization, predication, evaluation, warrants and backings awkward. At times it felt as if square pegs were being forced into round holes (Duschl et al. 1999, p. 421; also in Duschl 2007, p. 168-9)

The metaphor of forcing square pegs into round holes epitomizes the image that emerges from the early works of the argumentation strand - namely that scholars recognized the difficulty of taming dialogic argumentation by extrapolating talk units as one of the core elements in the Toulmin model. Further, in the passage above, Duschl et al. (1999) explicated the relation between this difficulty and the dialectical features of dialogic argumentation: Toulmin's description of the core elements in terms of their logical function is potentially out of sync with the dialectical nature of the recorded dialogic argumentation. Thus empirical studies that seek to resolve the difficulties that the Toulmin model causes must in the first place involve an interpretation of the dialectics of the dialogic argumentation.

This issue was also made explicit in what is undoubtedly the most significant contribution to the argumentation strand (in terms of citations at least) - namely Establishing the norms of scientific argumentation in classrooms by Driver et al. (2000). Driver et al. (2000) were concerned that the Toulmin model was insufficient when analyzing real dialogic argumentation for "[n]o recognition is given to the interactional aspects of argument" or to the fact that arguments generally are "influenced by [their] linguistic and situational contexts" (p. 294). According to Driver et al. (2000) what is needed for the Toulmin model to be a sufficient guide in the extrapolation of core elements is that the wider sequential context is taken into account: "the natural flow of conversation points are not necessarily developed sequentially and reference has to be made across extensive sections of the text to identify features of the argument” (p. 294). So Driver et al. (2000) also argued that empirical studies of students' dialogic argumentation, in which the analyst seeks to extrapolate Toulminian core elements, are parasitic to an interpretation of the individual talk units against the background of its place and role in the dialectical context. But beyond this recognition, Driver et al. (2000) provided no description - even in embryotic form - of a regimented procedure for how analysts consult the dialectical features of dialogic argumentation.

A trend emerges from these primary contributions to the early argumentation strand. First, the analysts who used the Toulmin model faced difficulties pertaining to which generic core element a given talk unit should be extrapolated as. Second, because of these difficulties the analyst needed to consider the dialectical features of the occurred dialogic argumentation. The analyst, that is, needed to consider the dialectics of the dialogue either by attending to the wider sequential context as Driver et al. (2000) proposed, by looking "forward" and "backward" in the argument sequences as Kelly et al. (1998) did, or by attending to "epistemic operations" and marking dialectical moves such as "requests", "oppositions" and "concessions" as Jiménez-Aleixandre et al. (2000) did. Third, the analyst's interpretation of the dialectical features of the dialogic argumentation was only referred to rather than explicitly explained and discussed. So while it is evident that some 
dialectical interpretations were made, it is unclear what that interpretational work consisted of and how topical interpretative decisions were made.

\section{A New Operationalization of the Toulmin Model}

The two papers Enhancing the quality of argumentation in school science (Osborne et al. 2004) and TAPping into argumentation (Erduran et al. 2004) defined the gold standard for how scholars in the argumentation strand operationalized the Toulmin model in subsequent years. The primary outcome of the two papers, in particular of Erduran et al. (2004), was the authors' proposal for a regimented procedure for the use of the Toulmin model that could possibly be used to elucidate a variety of research questions within (science) education. As such, their aim was to "improve the use of TAP [Toulmin's Argumentation Patterns]" (Erduran et al. 2004, p. 931) in a way that circumvents the analytical difficulties and in a way that would make the Toulmin model attractive for investigations of "the quantity and quality of argumentation" in science classrooms on a larger scale (Erduran et al. 2004, p. 916).

The fulcrum of the regimented procedure proposed in Erduran et al. (2004) and Osborne et al. (2004) is a coding scheme that can be used to classify individual arguments in one of five levels of sophistication or complexity (cf. Erduran et al. 2004, pp. 926-7; Osborne et al. 2004, p. 1008). In this coding scheme "better quality arguments" are classified on a higher level in the scheme (Erduran et al. 2004, p. 927). The qualitative measure that Erduran et al. (2004) used concerned the type, number, and quality of Toulmin's core elements in a given argument (cf. p. 928). Arguments that consist only of claims (in particular oppositional claims - claims, that is, against other claims or against counterclaims) are situated on the first level. Arguments that also involve some sort of justification belong on the second level. Arguments that — beside claim and justification — also involve "the occasional weak rebuttal" (p. 928) belong on the third level, while arguments that involve one or more rebuttals — that are strong in the sense that they "make a clear, self-evident connection to the data supporting the original claim" (p. 929) — belong to levels four and five, respectively.

Against the background of this coding scheme, it is possible to spell out - in skeletal form -Erduran et al. (2004) and Osborne et al. (2004) regimented procedure for using the Toulmin model: The analyst must (i) identify argumentative sequences in the data Erduran et al. (2004) "focused on those instances where there was a clear opposition between" the participants (p. 920-1) - (ii) identify argument cores by extrapolating core elements from the identified argument sequences under the guide of a revised Toulmin model, (iii) classify each of the extrapolated argument cores under one of the five levels of sophistication, and (iv) collect and compare the development of frequencies of arguments of different levels of sophistication over time or across contexts.

Needless to say, this quantification of the quality of arguments speaks to those scholars who are interested in large-scale studies of the quality of argumentation in science education. Indeed, Erduran et al.'s operationalization of the Toulmin model, in general, and the five-level coding scheme, in particular, has been adopted in many contexts: The coding scheme has been applied in an unaltered fashion in other studies (Aufschnaiter et al. 2008; Osborne 2005; Simon 2008; Zeidler et al. 2006); it has been extended and elaborated by others in the strand (Chin and Osborne 2010; D. Clark and Sampson 2007; Skoumios 2008); it has been used in parallel with other analytical approaches (D. Clark and Sampson 2008; Shea et al. 2011; Simon and Johnson 2008; Wishart et al. 2011); it has inspired scholars to devise similar coding schemes (Dawson and Venville 2009; Sadler and 
Donnelly 2006; Sadler and Fowler 2006); and it has been discussed by and inspired many other studies (e.g. Aufschnaiter et al. 2007; Gott and Duggan 2007; Maloney and Simon 2006; Molinatti et al. 2010; Okada and Shum 2008; Ravenscroft and Mcalister 2008; Wu and Tsai 2007).

The first two steps in the regimented analysis procedure proposed by Erduran et al. (2004) are of primary interest for this paper. The issue is how the authors proposed to regiment the procedure of identifying points of opposition among students and of extrapolating argument cores at those points according to the Toulmin model. The regimented procedure, which Erduran et al. (2004) proposed, hinges on (a) argumentative indicators - i.e. specified words or phrases that indicate to the analyst the presence of an opposition or of one of the Toulminian core elements — and (b) that inter-rater reliability can be established on the basis of using such indicators as cues for coding (cf. Erduran et al. 2004, pp. 920-3; Osborne et al. 2004, p. 1008).

In the first step, Erduran et al. (2004) sought to "identify episodes of opposition and dialogical argument" (p. 927). Their focus was on "explicit" (p. 927) or "genuine" (Osborne et al. 2004, p. 1007) episodes in which students had opposing standpoints. Such episodes, the authors stated, were indicated by words or phrases such as "but," "I disagree with you," "I don't think so," (Erduran et al. 2004, p. 927). In essence, this first analytical step is very similar to how Kelly et al. (1998) coded their data for "challenges" and to how JiménezAleixandre et al. (2000) apparently coded their data for "oppositions". But the new idea of Erduran et al. (2004) and Osborne et al. (2004) was the use of argumentative indicators so as to regiment the analysis procedure.

Erduran et al. (2004) also suggested the use of argumentative indicators for identifying core elements in the second step of the procedure: "[T]he data for the argument [...] is often preceded by words such as "because," "since," or "as"” (Osborne et al. 2004, p. 1006); and words such as "so" typically mark that the speaker is "reaching conclusions from data" (Erduran et al. 2004, p. 919). It has to be noted that the approach of looking for argumentative indicators in order to extrapolate core elements had been used before by Jiménez-Aleixandre and Pereiro-Muñoz (2002) but they only mentioned indicators "such as 'because' or 'since"' (p. 1177).

In order to further stabilize the extrapolation of core elements, Erduran et al. (2004) divided the analytical work into two phases. First, the analyst should identify claims and possible grounds (a concatenation of data, warrants and backings) for the claim and the possible rebuttals of the argument for the claim (cf. Erduran et al. 2004, p. 920). According to the authors, these core elements are "first-order elements" (Osborne et al. 2004, 1006). Second, the analyst may venture into identifying "second-order elements which are the components of the grounds for the claim - that is, the data, warrants, and backings" (Osborne et al. 2004, 1006). Though the authors indicated "that there is inevitably a process of interpretation to be made" (Osborne et al. 2004, p. 1006) in the process of extrapolating core elements, "there was little problem in distinguishing claims or rebuttals" (p. 926).

The way that Erduran et al. (2004) and Osborne et al. (2004) proposed this regimented analysis procedure raises some issues. It is difficult to get a sense of the conceptual foundation of Erduran et al.'s (2004) identification of oppositional episodes (cf. p. 927; Osborne et al. 2004, p. 1007). As argued above, oppositions or challenges can take different forces and degrees; indicators such as "I disagree with you", and "I don't think so" may represent different forces of a "mixed" form of disagreement, whereas an indicator such as "but" may represent a "nonmixed" form of disagreement (such as casting doubt, or merely refraining from endorsement) (Eemeren and Grootendorst 1992, p. 21ff.). While in principle it could be possible to concatenate these different forces and forms of 
disagreement into a generic concept of opposition, the fact that the authors did not discuss what they took an oppositional episode to be obscures the readers understanding of what analytical yardstick was used to identify oppositional episodes.

Further, the few remarks that Erduran et al. (2004) gave on how they classified rebuttals according to their strength suggest that the classification happened on the basis of a dialectical interpretation. Erduran et al. (2004) defined a strong rebuttal as making "direct reference to a piece of evidence (data, warrants, or backings) offered, thereby engaging with a presented argument" (p. 921); so a rebuttal that "does not make a clear, self-evident connection to the data supporting the original claim" is a "weak rebuttal" (p. 929). This would mean that in order to judge whether a given talk turn can be extrapolated as a strong rebuttal, the analyst must ipso facto look at its coherence with other talk turns in its context. The analyst must, that is, essentially attend to the rebuttal in its dialectical context and evaluate it from that perspective. However, Erduran et al. (2004) and Osborne et al. (2004) did not describe the yardstick used to assess the degree to which a particular rebuttal makes reference to pieces of evidence given at another place in the dialogue.

This leads to a more general issue: Beyond providing three typical argumentative indicators for speakers eliciting a premise, Erduran et al. (2004) did not discuss which argumentative indicators were used to identify and extrapolate core elements in general, and why these indicators were used. Other disciplines have spawned numerous works on the many different types of argumentative indicators in discourse (Fraser 1975; Pomerantz 1984a, b; Snoeck Henkemans 1992; van Eemeren, et al. 2007). Indeed, it has been a longstanding discussion in argumentation theory whether and how specific argumentative indicators can be used as analytical guides in the analysis of argumentative discourse (Katriel and Dascal 1984; Snoeck Henkemans 1996; van Eemeren and Grootendorst 1982; van Eemeren et al. 2007; Walton and Krabbe 1995). But such a discussion is not reflected in Erduran et al. (2004) and this again shrouds their analytical yardstick.

It is important to note that the rationale behind using argumentative indicators is that the analyst conceptualizes the recorded argumentative discourse as sequential in the sense that she is analyzing a conversational exchange that consist of moves and countermoves that relate to one another (van Eemeren, et al. 2007; see also Krabbe 1999; Walton 1999). In other words, to believe in the utility of argumentative indicators is to believe that speakers in specific situations express themselves in specific fashions, and that this fashion is a function of what happened before and of what the speaker anticipates will happen next. Thus, in the terminology of this paper, the use of argumentative indicators as guides when extrapolating argument cores from argument sequences, may be parasitic on, or even a part of, an interpretation of the dialectical features of argumentation. For example it may depend on the dialectical context whether the use of 'therefore' marks that a speaker will now elicit data or whether the speaker provides an explanation (van Eemeren et al. 2007). Likewise 'but' only in some cases mark an explicit challenge to a standpoint, in some cases it merely indicates doubt on the content of another talk turn, and in other cases it may even indicate other dialectical moves such as dissociating various aspects of an issue (as in "I was not talking about football but handball") that also play a role in the dialectics of argumentation (cf. e.g. Rees 2009). Further, a number of standard indicator words such as 'because', 'therefore', 'so' and, 'since' do not necessarily indicate that an argument is being made; they may just as reliably indicate an explanation — a discursive act which is fundamentally different from an argument (Govier 2010). Sorting this out is an affair of interpreting on the dialectics of the exchange at hand. Thus the intense interpretation that Erduran et al. (2004) went through — in order to decide whether a given talk unit was to be 
coded as this or that core element - must have been a dialectical analysis - even though it was not identified as such.

Erduran et al. (2004) were able to reach a satisfactory inter-rater reliability (p. 922; Osborne et al. 2004, p. 1008). Thus the reliability is not in doubt. In fact, reliability may not even be the interesting feature to look for. The point to note is that the reliability was a "product of the significant time devoted to resolving disagreements" among the coders (p. 920). Indeed, as Erduran et al. (2004) emphasized, the extrapolation of argument cores requires intense "interpretation" (p. 922), for in ordinary argumentative talk there are not always conspicuous indicators that uniformly mark that a particular talk unit is to be coded as a token of a generic core element. The intense interpretations that go into extrapolating talk units as core elements, the discussion among coders, and the final analytical decisions are in themselves highly interesting and deserve to be illuminated. Lunsford (2002), for example, has argued that — in educational research in general these is a lack of transparency of these interpretations, discussions, and decisions in Toulminian studies of students' argumentative discourse: "What tend to remain invisible are the numerous decisions the analysts must make to match specific pieces of data to the Toulminian codes, as well as the negotiations among coders over different possible applications of the model" (Lunsford 2002, p. 115).

Summary and Discussion of the uses of the Toulmin model

The purpose of the reviews above has been to highlight (i) that concrete operationalizations of the Toulmin model require that an interpretation of the dialectical features of the dialogical argumentation precedes the actual use of the Toulmin model; further, (ii) that in science education this type of interpretation that precedes the use of the Toulmin model has rarely been recognized as what it actually is - namely, an interpretation of the dialectical features of dialogical argumentation; and finally (iii) that even though this immense amount of interpretation has been recognized as a required part of the analysis procedure, the decisions that analysts made in that interpretation remain implicit.

Within the argumentation strand in science education, the necessity to investigate and interpret the dialectical features of dialogic argumentation has largely arisen in a roundabout way. The investigation of the dialectical features has primarily served an instrumental purpose of preparing the analyst for extrapolating Toulminian core elements from dialogic argumentation. In short, the interest in dialectical features has mainly arisen from the difficulties that permeate Toulminian analysis. This is unfortunate because the interpretation of dialectical features is a complex affair that merits substantial documentation and discussion. It should not be stowed away as a preparatory interpretation. Also it puts to the question the rationality of reducing argumentative discourse to core elements as a way of conducting large-scale studies.

So far this paper has concentrated largely on the use of the Toulmin model in empirical studies in science education. But the trend of the use of the Toulmin model for making dialectical interpretations is a manifestation of a deeper-rooted problem. Within argumentation theory and philosophy, it has been argued that the monological view afforded by the Toulmin model cannot meaningfully be applied to the complex dialogic dynamics of everyday argumentation (e.g. Fulkerson 1996; Habermas 1984; Johnson 1981a, 2002; Lynch 1982; Primatarova-Miltscheva 1987; van Eemeren et al. 1987; Willard 1976; Wohlrapp 1987). So though the Toulminian analyst may intend to investigate dialogic argumentation, her direct object of study is monologic - it is dialogic only in 
terms of the distant dialogic context in which the object of study was recorded. This puts to the question the a priori consistency of the Toulmin model. Indeed, the key tenet of the discursive paradigm that emerged within the social sciences and philosophy in the $20^{\text {th }}$ century is that no talk unit or part of a dialogue can be categorized or extrapolated as anything at all without attending to its relation parts of the dialogue (e.g. Habermas 1984; Schlegoff 1988). So the fundamental problem is that the Toulmin model simply does not include the conceptual tools that are needed in order to understand and thematise the dialogic context it presupposes for everyday non-analytical argumentation (Smith 1995).

From an a priori perspective, then, empirical studies that apply the Toulmin model are forced to supplement it with another framework that affords the dialectical interpretation that the Toulmin model manifestly requires before it can be applied. But such supplements cannot be chosen haphazardly. Any supplementing framework must be in a priori agreement with the foundational ontological tenets of the Toulmin model. It seems at this point that the argumentation strand is required to discuss in more detail, which frameworks might fit if the strand wishes to continue some form of use of the Toulmin model. Some scholars have taken the ultimate consequence of this disconcerting predicament and have approached students' dialogic argumentation explicitly from a dialectical perspective. The following section outlines some of these contributions.

\section{Dialectical Studies in Science Education}

One of the strongest advocates for attending explicitly to the dialectical features of students' argumentation has been Duschl (2007) who has proposed that science education researchers use Walton's framework for presumptive reasoning. According to Walton (1996), presumptive reasoning is a special type of argumentation that permeates everyday dialogic argumentation: For example "John's hat is not on the peg. Therefore John has left the house" (p. 17). In such argumentation the speaker draws a conclusion partly based on the tacit premise (the presumption) "If John's hat is not on the peg, then (we can normally expect), he has left the house" (p. 17). Walton's (1996) notion of presumptive reasoning is a way to spell out the dialogue logic of dialectical argumentation: Presumptive reasoning involves conclusions that are "defeasibly drawn from the premises rather than strictly implied by the premises" (p. 17); and if the antagonist present a sound argument for her standpoint, the opponent has to either accept the conclusion or rebut the argument. In other words, "[w]ith presumption then, the burden of (dis)proof lies on the respondent, not on the proponent" (Walton 1996, xii; see also p. 10). For Walton (1996), a sound argument is one in which the speaker follows one of 25 recognized argumentation schemes that fits the dialogic context of the discussion; and each scheme is followed by a list of "critical questions" that mark criteria for the cogency of the delivered argument (Walton 1996, pp. 46-110). If an opponent attempts to rebut a delivered presumptive argument she would ideally begin to scrutinize the critical questions.

Duschl et al. (1999; see also Duschl 2007) applied Walton's framework in an investigation of students' argumentative discourse in small group interviews. The procedure that can be distilled from Duschl (2007) is that the analyst interpreted argument sequences in order to identify one of nine different argumentation schemes, and thereby establishes a quantitative measure of the relative number of occurrences of a given scheme under changing circumstances or over time (cf. p. 169-170). In order to guide the identification most schemes were followed by a number of argumentative indicators or conversational markers. For this approach, just like for the Toulmin model, there is a substantial obstacle 
of how to determine which type of scheme a given argument follows. In order to circumvent this obstacle, Duschl et al. (1999; see also Duschl 2007) collapsed the schemes into four categories. It is possible that for an explicitly dialectical framework such as Walton's, this difficulty is less problematic than it is for the Toulmin model. To recall, the main problem that arose from the difficulty of extrapolating individual core elements was that the analyst had to do interpretative work on the dialectical features that could not be conceptualized from within the Toulmin model. But, in order to assess whether this interpretative problem is also an issue for Walton's framework, more theoretical discussions and empirical studies are needed. And there are indeed indications that more such work will appear in the near future. For example, Castells et al. (2009) conducted a similar type of study of the frequency of selected argumentation schemes in students' discourse - although they interwove Walton's notion of argumentation schemes with that of Perelman and Olbrechts-tyteca (1969).

It seems straightforward, however, that Walton's framework could also be used on smallscale studies that go deeper into selected cases of interesting argument sequences rather than comparing frequencies of schemes under different circumstances or over time. In any case, Duschl (2007) appears to be correct in asserting that Walton's framework, in comparison to the Toulmin model, more adequately fit the discourse structures (e.g., dialectical and rhetorical) and reasoning sequences"that are typical for group discourse such as the object of study of the argumentation strand" (p. 169) and that "[p]resumptive reasoning analyses seem to be a natural entry point for the assessment and development of student's argumentation strategies" (p. 173).

However, one rebuttal may be appropriate at this place. There are indications that Walton's notion of presumptive reasoning may be at odds with a very common form of practical argumentation, namely that of deliberative argumentation in which two or more speakers deliberate about what to do (not what is true). As Kock (2007a) has argued, there are many instances of practical deliberation were it would be wrong to suggest that just because an argument is "not rebutted, such an argument is strong enough to immediately mandate the decision (albeit in a presumptive way); and it is just as wrong to suggest that if a pertinent critical question is raised about the argument, then it is rebutted and [...] dealt with." (p. 93). For example, in most political discussions, an arguer who does not successfully rebut her opponent's argumentation will hardly succumb and agree with the standpoint of her opponent; and, Kock (2007b) argues, this is tolerable as long as she is observant of her other dialectical obligations. In short, there can be legitimate dissensus. From the perspective of Kock (2007a), the notion of presumptive reasoning is more ideally fitted for argumentation about propositions - rather than proposal about what to do. For the science education context this is important because if this is so, then Walton's framework seems well fitted for scientific argumentation about propositions, but not for socio-scientific argumentation about, for example, whether gene therapy should be allowed.

In a study of peer argumentation in small student groups during scientific inquiry activities Kim and Song (2005) explicitly attended to the "overall structure of argumentation involving several people" and "the process of argumentation rather than the form and content of the argument" (p. 215). The study by Kim and Song (2005) was explorative: Rather than using a predetermined coding scheme for analyzing their multifarious data types, they inductively constructed a scheme during their analysis. Some of the dimensions of the dialectical features of the discourse that Kim and Song (2005) focused on concerned the types of argumentative "strategies" that students would use in the discussions, and the discussion "stages" in terms of the dialectical "purpose" of a series of "conversational turns" (p. 219). For example they found that while some argumentative 
strategies pertained to the "cognitive" content of the argumentation (e.g. "questioning", "elaborating" etc.), other strategies pertained to the "social", or overall dialectical, aspects of the discussion ("conflict inducing" or "cooperative inducing" strategies) (pp. 221-223). This is resonant with some of the findings of Leitão (2000) in social psychology. Kim and Song (2005) also found that discussions go through stages of "focussing", "debating", "exchanging", and "closing" (p. 219).

Kim and Song's (2005) study was explicitly interpretative and was markedly grounded on previous expositions of conversational interaction. Such small-scale interpretative studies necessarily serve a different purpose than the studies that quantify larger amounts of data and score according to an a priori coding scheme. The force of the study of Kim and Song (2005) is the explicit role that their intense dialectical interpretations play in the report paper on the study.

In another small-scale study, Naylor et al. (2007) applied a specially designed model (the "Downing model") for analyzing "the nature of the interaction between the individuals" who participated in the study (p. 22; emphasis added). In particular they focused on how the interactional dynamics changed in students' group discussions when the teacher was present (cf. p. 32). Though the "Downing model" includes seven levels, it is not hierarchical; and while some of the levels - such as level 3 "[p]upils begin to offer grounds to support their claims" (p. 23) - seem to resemble levels in the coding scheme of Erduran et al. (2004), other levels indicate the attention to the interactional features of students' argumentation. For example, level 5 (“'[p]upils respond to ideas from others in the group") and level 6 ("[p]upils are able to sustain an argument in a variety of ways") (Naylor et al. 2007, p. 23). As in the case of the paper by Kim and Song (2005), the paper of Naylor et al. (2007) presents, interprets and discusses multiple and extensive transcripts of the recorded dialogic argumentation. One of the aspects of young science students' discussions that Naylor et al. (2007) were able to document was that "given a suitable stimulus" even young pupils "can and do engage in argumentation" which they sustain over considerable time (p. 36); and further, that the way in which students in their study argued indicated that they co-constructed their arguments dialectically "rather than viewing argumentation as confrontational" (p. 36).

Nielsen (2010, see also Nielsen forthcoming) has proposed another dialectical approach to students' dialogic argumentation in the context of a study on how science facts and human values are interweaved in small group discussions on a socio-scientific dilemma. The recorded dialogic argumentation in that study was approached in different analytical steps (cf. Nielsen 2010, forthcoming). First, each talk turn in the argument sequences was inductively coded so as to interpret which issue an individual talk turn was about. This coding led to the identification of a handful of key thematic issues for each discussion. Second, select argument sequences of each discussion were analyzed using a generic approach from argumentation theory - normative pragmatics (Goodwin 2001; Jacobs 2000; van Eemeren and Houtlosser 2007). In this step the objective was to interpret, from an argumentation theory perspective, both the content (what was said?) and the design (how was it said?) of the interactive messages that the students elicited during the discussion. Third, the normative pragmatics analysis culminated in an interpretation of the design and content of sequences of talk turns against the background of the thematic issues of the discussion. In that way, the overall objective of this form of analysis was to identify different argumentative strategies in which students blurred the fact-value distinction, to explain how these different strategies work argumentatively, but also, more importantly, how such strategies function within the discussion as a dynamic and organic whole. Nielsen (2010, see also Nielsen forthcoming) found that the argumentative strategies in which 
students invoke science alongside value claims or judgments can be dialectically complex - in the sense that some of the argumentative strategies that students conspicuously used involved subtle challenges to others and were executed in several talk turns at different places in the overall discussion sequence.

So while there have been a small number of studies in science education that attend directly and explicitly to the dialectical features of students' argumentation, it is still too soon to portray a general tendency among these studies beyond their common dialectical focus on dialogic argumentation.

\section{Concluding Remarks}

This paper has presented an argument for the necessity of a thorough theoretical discussion in the argumentation strand about how to understand and analyze the dialectical features of students' dialogic argumentation. The dialectical features, which are operative when students collaboratively argue for and against a standpoint, are interesting from an educational perspective; but, more importantly, it has been impossible for analysts to avoid interpreting these features, even if those analysts have set out to investigate non-dialectic aspects of students' argumentation. Thus the argumentation strand has, since its beginning, struggled to come to terms with the dialectical features of its object of study. The paper has further argued that the interpretative decisions and discussions of analysts have mostly not been communicated in a clear way. And it is still to soon to gather a general overview of the studies that explicitly set out to interpret the dialectical features of students' discourse; for these studies are few in numbers and still emerging. From these points emerge five key issues for the continued scholarly debate within the argumentation strand in science education.

The first issue pertains to the object of study of the argumentation strand. As this paper has attempted to show, most scholars in the strand have set out to investigate dialogic argumentation. But while the strand's standard definition of dialogic argumentation implies that such argumentation is dialectical, the dominant approach within the strand has been attempts to reduce the dialectical nature of discourse to measurable constructs of core elements. This suggests that there has been a mismatch between the intended object of study and the analytical approaches used to investigate that object of study. In order to resolve this the first issue that the argumentation strand must address is how dialogic argumentation should best be conceptualized from a science education perspective.

It has been thematic for the argumentation strand that attention to the dialectical features of students' argumentation has been motivated by difficulties of applying the Toulmin model. Analysts have thus largely seen themselves forced to adjust or add supplementary approaches to the Toulmin model. But it is manifest that, if future attempts to adjust the Toulmin model or to crossbreed it with other analytical frameworks are to succeed, then these adjustments or added analytical frameworks must be explicitly built to guide the analyst in her interpretation of the dialectical features of students' argumentation. But this, in turn, means that the scholars of the strand need to revisit what they see as viable analytical frameworks in general. Thus the second issue, which the argumentation strand needs to address, is this: Given a firm conceptualization of dialogic argumentation, which available analytical frameworks and approaches allow science education analysts to analyze the dialectical features of dialogical argumentation?

On the face of it, the Toulmin model has many advantages. The analyst is able to quantify large amounts of qualitative data, and can compare patterns of core elements across subjects, contexts, and time; and as a model, the Toulmin model potentially enables 
researchers to reconstruct, structure, and organize messy argumentation in order to get an overview of the situation (Andrews 2005). So while there are some disconcerting theoretical problems with the Toulmin model, it does propose itself for semi large-scale quantitative studies. The third issue for the argumentation strand is, then, how to salvage the appealing aspects of frameworks such as the Toulmin model that focus on core elements of arguments without having to face the substantial problems of the original Toulmin model.

Connected with the third issue is a more general and strategic issue. There will always be a certain trade off between having measurable constructs in the form of (informal) logical relations between core elements, on the one hand, and taking account of the dialectical context in which they originated, on the other. But where should the argumentation strand stake its money in the nearest future? Thus the fourth issue that the strand needs to address is whether the strand can better aid science education by large scale studies that focus on the (informal) logical relations in students' discourse or on smaller studies that are more explorative of students' argumentative discourse.

In any case it is crucial that the strand finds a viable solution to the practical problem of how to communicate and discuss the dialectical interpretation and interpretative decision that are a natural part of argumentation studies. From the reviews in this paper it is manifest that this is an aspect that deserves much more attention. The scholars of the argumentation strand may need to look in more detail to other fields that study discourse, but this will surely not be enough for the same problems are due to exist there as well. But the issue remains for the argumentation strand to address: Exactly how and in which forums should scholars communicate to, and discuss with, other scholars how the dialectical features were interpreted in a given study and why?

It is clear that such issues cannot be addressed in a vacuum. Scholars of the argumentation strand have to look to science education as an overarching endeavor, other scholarly fields, practitioners, and policy makers in order to properly discuss these issues. Nor do such issues have determinate answers. Thus the task of resolving these issues is similar to the activities that we in the argumentation strand love to study: The rewarding part is not the final claim or decision, nor is it the individual premises that substantiate it; the progress lies in the dialectics of the continued discussion.

\section{References}

Andrews, R. (2005). Models of argumentation in educational discourse. Text: Transactions of the Society for Textual Scholarship, 25(1), 107-127.

Aristotle. (1997). Topics. Books I and VIII, with excerpts from related texts (trans: Robin Smith). Oxford: Clarendon Press.

Aufschnaiter, C. V., Erduran, S., Osborne, J., \& Simon, S. (2007). Arguments and the learning of science. In R Pintó \& D Couso (Eds.), Contributions from Science Education (pp. 377-88). Dordrecht: Springer.

Aufschnaiter, C. V., Erduran, S., Osborne, J., \& Simon, S. (2008). Arguing to learn and learning to argue: case studies of how students' argumentation relates to their scientific knowledge. Journal of Research in Science Teaching, 45(1), 101-131.

Beard, D. (2003). Informal logic. Review of Communication, 3(3), 254-259.

Berland, L. K., \& Mcneill, K. L. (2010). A learning progression for scientific argumentation: understanding student work and designing supportive instructional contexts. Science Education, 94(5), 765-793.

Bermejo-Luque, L. (2006). Toulmin's model of argument and the question of relativism. In D. Hitchcock \& B. Verheij (Eds.), Arguing on the Toulmin Model (pp. 71-85). Dordrecht: Springer.

Blair, J., \& Johnson, R. (1987). Argumentation as dialectical. Argumentation, 1(1), 41-56.

Bricker, L. A., \& Bell, P. (2008). Conceptualizations of argumentation from science studies and the learning sciences and their implications for the practices of science education. Science Education, 92(3), 473-498. 
Castaneda, H. (1960). On a proposed revolution in logic. Philosophy of Science, 27, 279-92.

Castells, M., Erduran, S., \& Konstantinidou, A. (2009). Argumentation \& scientific conceptions in peer discussions: a comparison between Catalan \& English students. In G. Cakamaki \& M. F. Tasar (Eds.), Contemporary science education reserach: Scientific literacy and social aspects of science. A collection of papers presented at ESERA 2009 Conference (pp. 51-60). Ankara: Pegem Akademi.

Chambliss, M. J. (1995). Text cues and strategies successful readers use to construct the gist of lengthy written arguments. Reading Research Quarterly, 30(4), 778-807.

Chin, C., \& Osborne, J. (2010). Students' questions and discursive interaction: their impact on argumentation during collaborative group discussions in science. Journal of Research in Science Teaching, 47(7), 883-908.

Clark, G. (1990). Dialogue, dialectic, and conversation: a social perspective on the function of writing. Carbondale: Southern Illinois University Press.

Clark, D., \& Sampson, V. (2007). Personally-seeded discussions to scaffold online argumentation. International Journal of Science Education, 29(3), 253-277.

Clark, D., \& Sampson, V. (2008). Assessing dialogic argumentation in online environments to relate structure, grounds, and conceptual quality. Journal of Research in Science Teaching, 45(3), 293-321.

Cooley, J. (1959). On Mr. Toulmin's revolution in logic. The Journal of Philosophy, 56(7), $297-319$.

Cowan, J. (1964). The uses of argument - an apology for logic. Mind: A Quarterly Review of Philosophy, 73 (289), 27-45.

Dawson, V., \& Venville, G. (2009). High-school students' informal reasoning and argumentation about biotechnology: an indicator of scientific literacy? International Journal of Science Education, 31(11), 1421-1445.

Driver, R., Newton, P., \& Osborne, J. (2000). Establishing the norms of scientific argumentation in classrooms. Science Education, 84(3), 287-312.

Duschl, R. A. (2007). Quality argumentation and epistemic criteria. In S. Erduran \& M. P. JiménezAleixandre (Eds.), Argumentation in science education (pp. 159-175). Dordrecht: Springer Netherlands.

Duschl, R. A., \& Osborne, J. (2002). Supporting and promoting argumentation discourse in science education. Studies in Science Education, 38, 39-72.

Duschl, R. A., Ellenbogen, K., \& Erduran, S. (1999). Middle school students' dialogic argumentation. In M. Komorek, H. Behrendt, H. Dahncke, R. Duit, W. Gräber, \& A. Kross (Eds.), Research in science education: Past, present and future; Proceedings of the Second International Conference of the European Science Education Research Association (pp. 420-422). Kiel: IPN.

Eemeren, F. H. V., \& Grootendorst, R. (1992). Argumentation, communication, and fallacies: a pragmadialectical perspective. Hillsdale: L. Erlbaum.

Erduran, S. (2008). Methodological foundations in the study of argumentation in science classrooms. In S. Erduran \& M. P. Jiménez-Aleixandre (Eds.), Argumentation in science education, vol. 35 (pp. 47-69). Dordrecht: Springer Netherlands.

Erduran, S., Simon, S., \& Osborne, J. (2004). TAPping into argumentation: developments in the application of Toulmin's argument pattern for studying science discourse. Science Education, 88(6), 915-933.

Finocchiaro, M. A. (2006). Reflections on the hyper dialectical definition of argument. In P. Houtlosser \& A. van Rees (Eds.), Considering pragma-dialectics (pp. 51-62). Mahwah: Lawrence Erlbaum Associates.

Fraser, B. (1975). Hedged performatives. In P. Cole \& J. L. Morgan (Eds.), Syntax and semantics 3: speech acts (pp. 187-210). New York: Academic.

Freeman, J. B. (2005). Systematizing toulmin's warrants: an epistemic approach. Argumentation, 19, 1-46.

Freeman, J. B. (2009). Argument Strength, the Toulmin Model, and Ampliative Probability. In F. H. van Eemeren \& B. Garssen (Eds.), Pondering on Problems of Argumentation (pp. 191-205). Dordrecht: Springer.

Fulkerson, R. (1996). Teaching the argument in writing. Urbana: National Council of Teachers of English.

Garcia-Mila, M., \& Andersen, C. (2007). Cognitive foundations of learning argumentation. In S. Erduran \& M. P. Jiménez-Aleixandre (Eds.), Argumentation in science education (pp. 29-45). Dordrecht: Springer Netherlands.

Goldman, A. I. (1999). Knowledge in a social world. Oxford: Oxford University Press.

Goodwin, J. (2001). One Question, Two Answers. In H. V. Hansen, C. W. Tindale, J. A. Blair, R. H. Johnson \& R. C. Pinto (Eds.), Argumentation and Its Implications. Windsor, Ontario: Ontario Society for the Study of Argument, CD-ROM, ISBN:0-9683461-2-X, Retrieved from http://www.public.iastate.edu/ $\sim$ goodwin/pubs/goodwinone.pdf.

Gott, R., \& Duggan, S. (2007). A framework for practical work in science and scientific literacy through argumentation. Research in Science, 25(3), 271-291.

Govier, T. (2010). A practical study of argument (7th ed.). Belmont: Wadsworth Cengage Learning.

Gross, A. G. (1984). A comment on the uses of Toulmin. College English, 46, 10-14.

Habermas, J. (1984). The Theory of Communicative Action: Reason and the rationalization of society (trans: T. McCarthy). Boston: Beacon Press. 
Hample, D. (1992). The Toulmin model and the syllogism. In W. L. Benoit, D. Hample, \& P. J. Benoit (Eds.), Readings in argumentation (pp. 225-238). Dordrecht: Foris.

Hofstein, A., Kipnis, M., \& Kind, P. (2008). Learning in and from science laboratories: enhancing students' meta-cognition and argumentation skills. In C. L. Petroselli (Ed.), Science education issues and developments (pp. 59-94). New York: Nova.

Jacobs, S. (2000). Rhetoric and dialectic from the standpoint of normative pragmatics. Argumentation, 14(3), 261-286.

Jiménez-Aleixandre, M. P. (2007). Designing Argumentation Learning Environments. In S. Erduran \& M. P. Jiménez-Aleixandre (Eds.), Argumentation in science education (pp. 91-115). Dordrecht: Springer Netherlands.

Jiménez-Aleixandre, M. P., \& Erduran, S. (2007). Argumentation in science education: an overview. In S. Erduran \& M. P. Jiménez-Aleixandre (Eds.), Argumentation in science education (pp. 3-27). Dordrecht: Springer Netherlands.

Jiménez-Aleixandre, M. P., \& Pereiro-Muñoz, C. (2002). Knowledge producers or knowledge consumers? Argumentation and decision making about environmental management. International Journal of Science Education, 24(11), 1171-1190.

Jiménez-Aleixandre, M. P., \& Pereiro-Muñoz, C. (2005). Argument Construction and Change while Working on a Real Environment Problem. In Kerst Boersma, Martin Goedhart, Onno Jong \& Harrie Eijkelhof (Eds.), Research and the Quality of Science Education (pp. 419-31). Dordrecht: Springer.

Jiménez-Aleixandre, M. P., Rodriguez, A., \& Duschl, R. A. (2000). Doing the lesson or doing science: argument in high school genetics. Science Education, 84(6), 757-792.

Johnson, R. H. (1981a). Toulmin's bold experiment (i). Informal Logic Newsletter, 3(2), 1-12.

Johnson, R. H. (1981b). Toulmin's bold experiment (ii). Informal Logic Newsletter, 3(3), 1-9.

Johnson, R. H. (1995). Informal logic and pragma-dialectics: some differences. In F. H. van Eemeren, R. Grootendorst, J. A. Blair, \& C. Willard (Eds.), Proceedings of the Thirs ISSA conference on argumentation, volume I: Perspectives and approaches (pp. 237-245). Amsterdam: SicSat.

Johnson, R. H. (2002). Manifest rationality reconsidered: reply to my fellow symposiasts. Argumentation, 16 (3), 311-331.

Katriel, T., \& Dascal, M. (1984). What do indicating devices indicate? Philosophy and Rhetoric, 17, 1-15.

Keith, W., \& Beard, D. (2008). Toulmin's rhetorical logic: what's the warrant for warrants? Philosophy and Rhetoric, 41(1), 22-50.

Kelly, G., \& Chen, C. (1999). The sound of music: constructing science as sociocultural practices through oral and written discourse. Journal of Research in Science Teaching, 36, 883-915.

Kelly, G., Druker, S., \& Chen, C. (1998). Students' reasoning about electricity: combining performance assessments with argumentation analysis. International Journal of Science Education, 20(7), 849-871.

Kim, H., \& Song, J. (2005). The features of peer argumentation in middle school students' scientific inquiry. Research in Science Education, 36(3), 211-233.

Klumpp, J. (2006). Warranting arguments, the virtue of verb. In D. Hitchcock \& B. Verheij (Eds.), Arguing on the Toulmin Model (pp. 103-113). Amsterdam: Springer Netherlands.

Kock, C. (2007a). Is practical reasoning presumptive? Informal Logic, 27(1), 91-108.

Kock, C. (2007b). Norms of legitimate dissensus. Informal Logic, 27(2), 179-196.

Kock, C. (2007c). Dialectical obligations in political debate. Informal Logic, 27(3), 233-247.

Kolstø, S. D., \& Ratcliffe, M. (2007). Social aspects of argumentation. In S. Erduran \& M. P. JiménezAleixandre (Eds.), Argumentation in science education, vol. 35 (pp. 117-136). Dordrecht: Springer Netherlands.

Krabbe, E. (1999). Profiles of dialogue. In J. Gerbrandy, M. Marx, M. de Rijke, \& Y. Venema (Eds.), JFAK. Essays dedicated to Johan van Benthem on the occasion of his 50th birthday, III (pp. 25-36). Amsterdam: Amsterdam University Press.

Leitão, S. (2000). The potential of argument in knowledge building. Human Development, 43(6), 332-360.

Leitão, S. (2001). Analyzing changes in view during argumentation: A quest for method. Forum Qualitative Sozialforschung/Forum: Qualitative Social Research, 2(3). Retrieved from http://www.qualitativeresearch.net/index.php/fqs/article/view/907/1983.

Lunsford, K. (2002). Contextualizing Toulmin's model in the writing classroom. Written Communication, 19 (1), 109-174.

Lynch, M. (1982). Closure and disclosure in pre-trial argument. Human Studies, 5(1), 285-318.

Maloney, J., \& Simon, S. (2006). Mapping children's discussions of evidence in science to assess collaboration and argumentation. International Journal of Science Education, 28(15), 1817-1842.

Molinatti, G., Girault, Y., \& Hammond, C. (2010). High school students debate the use of embryonic stem cells: the influence of context on decision-making. International Journal of Science Education, 99999 (1), 1-17. 
Munneke, L., van Amelsvoort, M., \& Andriessen, J. (2003). The role of diagrams in collaborative argumentation-based learning. International Journal of Educational Research, 39(1-2), 113-131.

Naylor, S., Keogh, B., \& Downing, B. (2007). Argumentation and primary science. Research in Science Education, 37(1), 17-39.

Newman, S., \& Marshall, C. (1991). Pushing Toulmin too far: Learning from an argument representation scheme. Xerox PARC, Palo Alto, CA, USA, Technical Report SSL-92-45.

Nielsen, J. A. (2010). Functional roles of science in socio-scientific discussions. In Ingo Eilks \& Bernd Ralle (Eds.) Contemporary Science Education - Implications from Science Education Research about Orientations, Strategies and Assessment (pp. 83-96). Aachen: Shaker.

Nielsen, J. A. (forthcoming). Co-opting Science: A preliminary study of how students invoke science in value-laden discussions. Forthcoming in International Journal of Science Education.

Okada, A., \& Shum, S. B. (2008). Evidence-based Dialogue Maps as a research tool to investigate the quality of school pupils' scientific argumentation. International Journal of Research \& Method in Education, 31 (3), 291-315.

O'Keefe, D. (1977). Two concepts of argument. Journal of the American Forensic Association, 13(3), 121-128.

Orsolini, M., \& Pontecorvo, C. (1992). Children's talk in classroom discussions. Cognition and Instruction, 9 (2), 113-136.

Osborne, J. (2005). The role of argument in science education. In K. Boersma, M. Goedhart, O. Jong, \& H. Eijkelhof (Eds.), Research and the quality of science education (pp. 367-380). Dordrecht: Springer Netherlands.

Osborne, J., Erduran, S., \& Simon, S. (2004). Enhancing the quality of argumentation in school science. Journal of Research in Science Teaching, 41(10), 994-1020.

Pera, M. (1994). The discourses of science. Chicago: University of Chicago Press.

Perelman, C., \& Olbrechts-Tyteca, L. (1969). The new rhetoric: a treatise on argumentation. Notre Dame: University of Notre Dame Press.

Pomerantz, A. M. (1984a). Agreeing and disagreeing with assessments: Some features of preferred/ dispreferred turn shapes. In J. M. Atkinson \& J. Heritage (Eds.), Structures of social action. Studies in conversation analysis (pp. 57-101). Cambridge: Cambridge University Press.

Pomerantz, A. M. (1984b). Giving a source or basis: the practice in conversation of telling 'how I know'. Journal of Pragmatics, 8, 607-625.

Pontecorvo, C., \& Girardet, H. (1993). Arguing and reasoning in understanding historical topics. Cognition and Instruction, 11(3/4), 365.

Pontecorvo, C., \& Pirchio, S. (2000). A developmental view on children's arguing: the need of the other. Human Development, 43(6), 361-363.

Primatarova-Miltscheva, A. (1987). Sequence with concessive, adversative, and restrictive sentences and clauses and the simulation of dialogical argumentation patterns in monological discourse. In F. H. van Eemeren, R. Grootendorst, J. A. Blair, \& C. A. Willard (Eds.), Argumentation: Perspectives and Approaches (pp. 41-53). Dordrecht: Foris.

Ravenscroft, A., \& Mcalister, S. (2008). Investigating and promoting educational argumentation: towards new digital practices. International Journal of Research and Method in Education, 31(3), 317-335.

Reed, C., \& Rowe, G. (2005). Translating Toulmin diagrams: theory neutrality in argument representation. Argumentation, 19(3), 267-286.

Rees, M. V. (2009). Dissociation in argumentative discussions: a pragma-dialectical perspective. Dordrecht: Springer.

Sadler, T. D., \& Donnelly, L. (2006). Socioscientific argumentation: the effects of content knowledge and morality. International Journal of Science Education, 28(12), 1463-1488.

Sadler, T. D., \& Fowler, S. R. (2006). A threshold model of content knowledge transfer for socioscientific argumentation. Science Education, 90(6), 986-1004.

Sampson, V., \& Clark, D. (2008). Assessment of the ways students generate arguments in science education: current perspectives and recommendations for future directions. Science Education, 92(3), 447-472.

Schlegoff, E. (1988). Presequences and indirection: applying speech act theory to ordinary conversation. Journal of Pragmatics, 12, 55-62.

Shea, N., Duncan, R. G., \& Stephenson, C. (2011). Exploring Genetic Literacy: How Undergraduate Science Majors Reason About Authentic Genetic Dilemma. Paper presented at the annual meeting of NARST, April 3-6, Orlando, Fl.

Siegel, H. (1995). Why should educators care about argumentation? Informal Logic, 17(2), 159-176.

Simon, S. (2008). Using Toulmin's argument pattern in the evaluation of argumentation in school science. International Journal of Research and Method in Education, 31(3), 277-289.

Simon, S., \& Johnson, S. (2008). Professional learning portfolios for argumentation in school science. International Journal of Science Education, 30(5), 669-688. 
Skoumios, M. (2008). The effect of sociocognitive conflict on students' dialogic argumentation about floating and sinking. International Journal of Environmental \& Science Education, 3(3).

Smith, R. (1993). Aristotle on the uses of dialectic. Synthese: An International Journal for Epistemology, Methodology and Philosophy of Science, 96(3), 335-358.

Smith, P. C. (1995). Towards a discursive logic: Gadamer and Toulmin on Inquiry and Argument. In L. K. Schmidt (Ed.), The specter of relativsm (pp. 159-177). Evanston: Northwestern University Press.

Snoeck Henkemans, A. (1992). Analysing complex argumentation. The reconstruction of multiple and coordinatively compound argumentation in a critical discussion. Amsterdam: Sic Sat.

Snoeck Henkemans, A. (1996). Indicators of independent and interdependent arguments: 'anyway' and 'even'. In J. van Benthem, F. H. van Eemeren, R. Grootendorst, \& F. Veltman (Eds.), Logic and argumentation (pp. 77-87). Amsterdam: Koninklijke Nederlandse Akademie van Wetenschappen.

Toulmin, S. E. (1958). The uses of argument. Cambridge: Cambridge University Press.

Trent, J. (1968). Toulmin's model of an argument: an examination and extension. The Quarterly Journal of Speech, 54(3), 252-259.

van Eemeren, F. H., \& Grootendorst, R. (1982). The speech acts of arguing and convincing in externalized discussions. Journal of Pragmatics, 6(1), 1-24.

van Eemeren, F. H., \& Grootendorst, R. (2004). A systematic theory of argumentation: The pragmadialectical approach. Cambridge: Cambridge University Press.

van Eemeren, F. H., \& Houtlosser, P. (2007). The study of argumentation as normative pragmatics. Pragmatics: Quarterly Publication of the International Pragmatics Association, 15(1), 161-177.

van Eemeren, F. H., Grootendorst, R., \& Kruiger, T. (1987). Handbook of Argumentation theory: A critical survey of classical backgrounds and modern studies. Dordrecht: Foris.

van Eemeren, F. H., Houtlosser, P., \& Snoeck Henkemans, A. (2007). Argumentative indicators in discourse: A pragma-dialectical study. Dordrecht: Springer.

Verheij, B. (2005). Evaluating arguments based on Toulmin's scheme. Argumentation, 19, 47-71.

Walker, K., \& Zeidler, D. L. (2007). Promoting discourse about socioscientific issues through scaffolded inquiry. International Journal of Science Education, 29(11), 1387-1410.

Walton, D. N. (1996). Argumentation schemes for presumptive reasoning. Mahwah: L. Erlbaum Associates.

Walton, D. N. (1999). Profiles of dialogue for evaluating arguments from ignorance. Argumentation, 13, 5371.

Walton, D. N. (2000). The place of dialogue theory in logic, computer science and communication studies. Synthese: An International Journal for Epistemology, Methodology and Philosophy of Science, 123(3), 327-346.

Walton, D. N., \& Godden, D. M. (2007). Informal logic and the dialectical approach to argument. In H. V. Hansen \& R. C. Pinto (Eds.), Reason reclaimed (pp. 3-17). Newport News, VA: Vale Press.

Walton, D. N., \& Krabbe, E. (1995). Commitment in dialogue. Basic concepts of interpersonal reasoning. Albany: State University of New York Press.

Wenzel, J. (1993). Rhetoric and argumentation: an introduction. Informal Logic, 15(1), 1-3.

Willard, C. (1976). On the utility of descriptive diagrams for the analysis and criticism of arguments. Communication Monographs, 43(4), 308-319.

Willard, C. (1989). A theory of argumentation. Tuscaloosa: University of Alabama Press.

Wishart, J., Green, D., Joubert, M., \& Triggs, P. (2011). Discussing ethical issues in school science: an investigation into the opportunities to practise and develop arguments offered by online and face-to-face discussions. International Journal of Science Education, Part B, 1(1), 47-69.

Wohlrapp, H. (1987). Toulmin's theory and the dynamics of argumentation. In F. H. van Eemeren, R. Grootendorst, J. A. Blair, \& C. Willard (Eds.), Argumentation: perspectives and approaches (pp. 327335). Dordrecht: Foris.

Wu, Y., \& Tsai, C. (2007). High school students' informal reasoning on a socio-scientific issue: qualitative and quantitative analyses. International Journal of Science Education, 29(9), 1163-1187.

Zeidler, D. L., Osborne, J., Erduran, S., Simon, S., \& Monk, M. (2006). The role of argument during discourse about socioscientific issues. In D. L. Zeidler (Ed.), The role of moral reasoning on socioscientific issues and discourse in science education (pp. 97-116). Dordrecht: Springer.

Zohar, A. (2007). Science teacher education and professional development in argumentation. In S. Erduran \& M. P. Jiménez-Aleixandre (Eds.), Argumentation in science education (pp. 245-268). Dordrecht: Springer Netherlands.

Zohar, A., \& Nemet, F. (2002). Fostering students' knowledge and argumentation skills through dilemmas in human genetics. Journal of Research in Science Teaching, 39(1), 35-62. 